\title{
Sumari
}

Papers. Revista de Sociologia

Octubre-deseembre 2010, vol. 95, núm. 4, p. 875-1189

ISSN 0210-2862 (imprès)

http://ddd.uab.cat/record/35

http://ojs.uab.cat/index.php/papers

ISSN 2013-9004 (en línia)

879-884 Presentación. Análisis sociológico comparado de dos regiones: Andalucía y Cataluña

\section{Articles Monogràfic}

887-910 Camarero Rioja, Mercedes (Universidad Pablo de Olavide)

Las relaciones sociales como recurso estratégico para el desarrollo de la sociedad. El capital social disponible en Andalucía y en Cataluña. Papers, 2010, vol. 95, núm. 4, p. 887-910.

Palabras clave: capital social, índice sintético, calidad social, capital social vinculante, capital social aglutinante, sociología comparativa, Andalucía, Cataluña, España, Europa.

911-934 García Faroldi, Livia (Universidad de Málaga)

Nación y territorio. Análisis comparado del sentimiento nacionalista y la pertenencia a territorios en Andalucía y Cataluña. Papers, 2010, vol. 95, núm. 4, p. 911-934.

Palabras clave: nacionalismo, identificación geográfica, modernización política.

935-952 Requena Santos, Félix (Universidad de Málaga)

Desarrollo y movilidad social. Análisis comparado entre Andalucía y Cataluña. Papers, 2010, vol. 95, núm. 4, p. 935-952.

Palabras clave: movilidad social, desarrollo, Andalucía, Cataluña, estructura comparada. 
953-975 Ortega Gaspar, Marta (Universidad de Málaga)

El mercado de trabajo en Andalucía y Cataluña desde la perspectiva de género. Su evolución durante el período de 1995 a 2005. Papers, 2010, vol. 95, núm. 4, p. 953-975.

Palabras clave: cambio social, modernización, desigualdad social, mercado de trabajo, género, desigualdad entre comunidades autónomas.

979-1000 Herranz de Rafael, Gonzalo (Universidad de Almería)

Modernidad y xenofobia en Andalucía y Cataluña: un análisis comparativo. Papers, 2010, vol. 95, núm. 4, p. 979-1000.

Palabras clave: xenofobia, modernización, inmigración, estudio cuantitativo, Andalucía, Cataluña.

1001-1030 Gobernado Arribas, Rafael (Universidad de Málaga)

Desarrollo y modernización. Un estudio comparado entre las comunidades autónomas de Andalucía y Cataluña. Papers, 2010, vol. 95, núm. 4, p. 1001-1030.

Palabras clave: convergencia, indicadores de desarrollo, desigualdad de ingresos.

1031-1051 Fernández Alonso, Mercedes (Universidad de Málaga)

Valores y creencias en el proceso de modernización. Papers, 2010, vol. 95, núm. 4, p. 1031-1051.

Palabras clave: valores, materialismo, post-materialismo, modernización.

1053-1074 Martín-Lagos López, M. a Dolores (Universidad de Granada) Modernización y consumo en Andalucía y Cataluña (1995-2006). Papers, 2010, vol. 95, núm. 4, p. 1053-1074.

Palabras clave: individuación, consumo, objetos materiales, consumerismo, desarrollo, tecnología.

\section{Notes d'investigació Monogràfic}

1077-1103 Troyano Pérez, José Fernando (Universidad de Málaga) Movimientos de población en Andalucía y Cataluña (1995-2006). Una compración desde la teoría de la modernización. Papers, 2010, vol. 95, núm. 4, p. 1077-1103.

Palabras clave: movimientos de población, modernización social, ingreso declarado, años de escolarización, tamaño de población del municipio, homogeneidad territorial. 


\section{Articles Miscelànic}

1107-1128 Echavarren, José Manuel (Universidad Pablo de Olavide) Conceptos para una sociología del paisaje. Papers, 2010, vol. 95, núm. 4, p. 1107-1128.

Palabras clave: sociología del paisaje, híbridos, icono, lugar, espacio, construcción social de la naturaleza.

1129-1155 Aguilar Fernández, Susana (Universidad Complutense de Madrid) El activismo político de la Iglesia católica durante el gobierno de Zapatero (2004-2010). Papers, 2010, vol. 95, núm. 4, p. 11291155.

Palabras clave: grupo de interés, adversario político, Iglesia católica, políticas socialistas.

1157-1172 García Soidán, Pilar (Universidade de Vigo); Dios Poceiro, Herminia (Asociación de Desenvolvemento Rural Proder II); Villaverde López, Rebeca (Anova Multiconsulting); Rubiños López, Óscar (Universidade de Vigo)

La participación voluntaria en situaciones de emergencia. Papers, 2010, vol. 95, núm. 4, p. 1157-1172.

Palabras clave: emergencia, participación, voluntariado.

\section{Notes d'investigació Miscelànic}

1175-1186 Miguel Quesada, Francisco J. (Universitat Autònoma de Barcelona) Una experiencia de comunidad de aprendizaje virtual. El uso de nuevas TIC en el desarrollo colaborativo de recursos WWW para una asignatura. Papers, 2010, vol. 95, núm. 4, p. 1175-1186.

Palabras clave: aprendizaje cooperativo, comunidades virtuales de aprendizaje, uso didáctico de las nuevas TICs, entornos bimodales de aprendizaje.

\section{Ressenyes}

1187-1189 Uña Juárez, Octavio. Nuevos ensayos de sociología y comunicación (Maximiliano Fernández Fernández).

Normes de publicació a Papers. Revista de Sociologia Normas de publicación en Papers. Revista de Sociologia Guidelines for publication in Papers. Revista de Sociologia 